\title{
Genesis of the Northeast Brazil Upper-Tropospheric Cyclonic Vortex: A Primitive Equation Barotropic Instability Study
}

\author{
S. K. Mishra, V. Brahmananda Rao, and Sergio H. Franchito \\ Instituto Nacional de Pesquisas Espaciais, São Jose dos Campos, São Paulo, Brazil
}

(Manuscript received 2 August 2005, in final form 3 July 2006)

\section{ABSTRACT}

The primitive equation barotropic unstable linear normal modes are computed using an eigenvalue approach for daily latitudinal profiles of zonal flow in the upper-tropospheric layer of $100-350 \mathrm{hPa}$ before and after formation of cyclonic vortices during January 1993 and November 2001 off the coast of northeast Brazil. The wave kinetic energy equation for $t$ - and $v$-motion is presented. Equations are derived to isolate the contribution of divergence and other dynamical processes in the movement and growth of unstable modes. Numerical accuracy and physical nature of unstable modes are tested.

In a short span of 2-3 days, prior to formation of vortices, a progressive and a sharp intensification of the basic flow shear zone and its barotropic instability are seen with time. The horizontal structure, momentum transport, and zonal and meridional scales of the most unstable normalized wave are obtained and compared with the vortex extracted from the 200 -hPa observed winds.using a bandpass smoother. A close agreement is found between them. It is shown that the zonal and meridional scales of the preferred wave are related to the length scale of the shear zone. The wave is confined to the shear zone and its maximum amplitude is located at the latitude of maximum $\beta-\bar{u}_{y, .}$. The role of divergence in the movement and growth of the wave is investigated. The energetics of the unstable wave $u$ - and $v$-motion is computed, and it is inferred that the energy source for the growth of wave $w^{-}(v)$ motion is the energy conversion (work done by pressure force), which lies in the shear zone.

It is emphasized that a deeper insight regarding the genesis of the cyclonic vortex can be gained on the basis of stability analysis of daily observed zonal flow profiles, which may not be possible using idealized or mean profiles. An explanation for nonmanifestation of the instability in the monthly mean flow is provided.

\section{Introduction}

During the summer season of the Southern Hemisphere (December-February), synoptic-scale, transient, cyclonic vortices are frequently observed in the tropical upper troposphere over the South Atlantic Ocean off the coast of northeast Brazil (Virji 1981; Kousky and Gan 1981). They are generally known as upper-tropospheric vortices of northeast Brazil. The vortices are embedded in the quasi-stationary, midocean South Atlantic trough and move westward toward the quasi-stationary Bolivian high located over the continent of South America.

Kousky and Gan (1981) and subsequently Ramirez et al. (1999) compiled the various observed statistics related to the vortices. The largest number of vortices is

Corresponding author address: Dr. S. K. Mishra, B1/103 Nirmiti Horizon, New D. P. Road, Aundh, Pune 411007 , India. E-mail: skmishrapune@rediffmail.com formed in the month of January and generally no vortex is observed during the winter (May-September). The monithly frequency (number of vortex days in a month) during the summer is 2.4 ( 22 days).

They originate mainly in the $200-300-\mathrm{hPa}$ layer and are observed in the area $20^{\circ}-10^{\circ} \mathrm{S}, 45^{\circ}-25^{\circ} \mathrm{W}$. Furthermore, the vortices have a cold core at $300 \mathrm{hPa}$ and have an average westward speed of about $4-6 \mathrm{~m} \mathrm{~s}^{-1}$. They exhibit a pronounced southeast-northwest tilt with latitude. The wavelength associated with the initial stage of cyclonic vortex is around $3500 \mathrm{~km}$ (Kayano et al. 1997; Kousky, and Gan 1981). The convective activity is observed mainly away from the vortex center and particularly ahead of it, that is, to its west.

Mishra et al. (2001, hereafter MRG) studied the evolution of large-scale flow and an embedded cyclonic vortex at $200 \mathrm{hPa}$. They noted the following: (a) the development of a strong shear zone before vortex formation; (b) a strong barotropic interaction between vortex and large-scale flow; and (c) the zonal and me-

DOI: $10.1175 / J A S 3893.1$

(1) 2007 Amcrican Metcorologica! Society 
ridional scales of vortex strongly related to the shear zone scale instead of the Rossby deformation radius. These features indicate that the barotropic process dominates over the baroclinic one.

Rao and Bonatti (1987) computed the barotropic energy conversion at $200 \mathrm{hPa}$ during the summer of $1977 /$ 78 , when a number of vortices were observed over the area. They noted a weak energy transfer from zonal to eddy kinetic energy during the period. Recently, Mishra and Rao (2001, hereafter MR01) performed the energy budget analysis for an individual, representative cyclonic vortex. They found in the upper troposphere a sharp decrease (increase) in zonal kinetic energy during (before) the vortex formation, which is associated with its large transfer to eddy kinetic energy.

During the pre- and vortex periods, the baroclinic interaction is insignificant as indicated by the zonal to eddy available potential energy transfer. Furthermore, the zonal flow during the prevortex period satisfies the necessary condition of barotropic instability (Kuo 1949). These features strongly suggest that the barotropic instability is a possible mechanism for the initial formation of vortex. MR01 noted that changes in the mean encrgy parameters during the vortex period over their mean values during the prevortex period are large in the upper layer, $100-350 \mathrm{hPa}$, but insignificant in the lower layer, $500-1000 \mathrm{hPa}$, even though convection is active. Kuo (1978) found that the influence of latent heat is weak for slowly eastward-moving waves concentrated in the tropical upper troposphere. Furthermore, the effect of stable stratification is to restrict the disturbances either to the upper or to the lower level.

The barotropic instability of zonal flow is considered as the main dynamical mechanism for the origin of most incipient synoptic disturbances in the Tropics (Kuo 1973). Invariably, an idealized or a mean observed profile is used to investigate its unstable modes and compare then with the ensemble characteristics of observed disturbance. A stability analysis of daily zonal flow could lead to a better understanding of tropical disturbance.

The main purpose of this study is to examine the primitive equation, barotropic instability of day-to-day observed latitude-varying, vertically averaged zonal wind profiles in the layer 100-350 $\mathrm{hPa}$, before the formation of cyclonic vortices of northeast Brazil. The role of divergence and stratification in the unstable modes is to be examined. It is expected that such an analysis will provide a basis to understand the initial development of vortices.

\section{Data and synoptic discussion}

Reanalysis data of the National Centers for Environmental Prediction-National Center for Atmospheric
Research (NCEP-NCAR) are used. The data are 1200 UTC daily zonal (u) and meridional (v) wind components, temperature $(T)$, and geopotential height $(h)$ at all standard pressure levels for the relevant periods. The data are in $2.5^{\circ} \times 2.5^{\circ}$ latitude and longitude grid.

We have considered two observed vortices, whose details are as follows.

\section{a. Cyclonic vortex during 5-18 January 1993}

Three vortices formed and dissipated one after another during January 1993. Together they had a total lifetime of 19 days. A cyclonic vortex that occurred in early January 1993 over northeast Brazil is selected for the study. At $200 \mathrm{hPa}$ a weak vortex was first seen on 5 January around $9^{\circ} \mathrm{S}, 35^{\circ} \mathrm{W}$ and became an intense system the next day. It seems that the vortex formed in situ. The vortex can be seen as an intense system both in wind and geopotential height. The vortex did not show any movement during 5-6 January, but during 6-7 January it had moved in the northwest direction (INPE 1993). During the period 5-10 January, the average eastward speed of vortex is $0.5^{\circ} \mathrm{day}^{-1}$. Subsequently, the vortex moved westward. Hereafter, this vortex will be called VorJ93. The author and his collaborators have studied the evolution and energetics of this particular vortex (MRG; MR01). The prevortex period is considered to be between 1 and 4 January.

\section{b. Cyclonic vortex during 13-15 November 2001}

Three vortices formed and dissipated during November 2001 (INPE 2001). On eight different days at least one vortex can be seen during the month. The first cyclonic vortex was formed around 18 November. As its observed characteristics are not known, daily $u, v$, and $h$ at $200 \mathrm{hPa}$ in the global belt $35^{\circ} \mathrm{S}-15^{\circ} \mathrm{N}$ for the period 10-21 November were subjected to a bandpass smoother, which basically retains wavelengths of 1000 $3500 \mathrm{~km}$ (MRG).

An examination of the daily bandpass streamlines and height contours reveals the following. A pair of well-organized cyclonic and anticyclonic centers is seen on 13 November with a wavelength of $3000 \mathrm{~km}$. The cyclonic center is located at $5^{\circ} \mathrm{S}$ and $45^{\circ} \mathrm{W}$. The vortex will be known as VorN01. During 13-14 November the vortex has moved in the northeast direction with an eastward speed of $3.2 \mathrm{~m} \mathrm{~s}^{-1}$. The vortex cannot be seen in the observed height field during 13-15 November but it can be seen as a weak organized system in bandpass height field. As the system is weak and formed close to the equator, it is expected that the associated height variations are small. The system is nearly 3 times weaker than VorJ93 in terms of vorticity. The prevor- 
tex period for VorN01 is considered to be between 10 and 12 November.

\section{System of equations}

\section{a. Model equations and boundary conditions}

The effect of vertical stratification is incorporated as the vortex and its interaction with the large-scale flow is basically confined to the layer $100-350 \mathrm{hPa}$. A gravitationally stable three-layer system of homogeneous, in. compressible, inviscid and nonmixing fluids in hydrostatic balance is considered. The motionless top and bottom layers are infinitely deep, and the active niddle layer has a constant depth $H_{0}$, when at rest. Let $\left[\bar{\theta}_{b}\right]$, $\left[\bar{\theta}_{m}\right]$, and $\left[\bar{\theta}_{t}\right]\left(\left[\bar{\theta}_{b}\right]<\left[\bar{\theta}_{m}\right]<\left[\bar{\theta}_{t}\right]\right)$ denote the areaaveraged mean potential temperatures of the bottom, middle, and top layers, respectively. Here the bar denotes zonal average and the square bracket denotes latitude average.

The form of equations for the three-layer system is the same as that of a single layer except that the gravity, $g$, is replaced by the reduced gravity, $g^{*}$. The influence of vertical stratification on the motion of the middle layer is parameterized in the form of $g^{*}$. We use the nondimensional form of the equations for a better computational accuracy. Let $L_{0}\left(U_{0}\right)$ be the characteristic horizontal length (velocity) scale. The characteristic scalc for time (geopotential) is $L_{0} / U_{0}\left(U_{0}^{2}\right)$. The linear momentum and continuity equations governing the perturbations on the geostrophic flow $\bar{u}(y)$ in the middle layer can be easily obtained and written as

$$
\begin{aligned}
u_{t}^{\prime}+\bar{u} u_{x}^{\prime}-\left(f-\bar{u}_{y}\right) v^{\prime} & =-\phi_{x}^{\prime}, \\
v_{t}^{\prime}+\bar{u} v_{x}^{\prime}+f u^{\prime} & =-\phi_{y}^{\prime}, \\
\phi_{t}^{\prime}+\bar{u} \phi_{x}^{\prime}+\bar{\phi}_{y} v^{\prime}+\left(\phi_{0}+\bar{\phi}\right)\left(u_{x}^{\prime}+v_{y}^{\prime}\right) & =0,
\end{aligned}
$$

where $f=f_{0}+\beta y, \beta=f_{y}, f \bar{l}=-\bar{\phi}_{y}, \phi_{0}=\left(g^{*} L_{0}\right.$ $\left.U_{0}^{2}\right) H_{0}$.

Here the prime (') denotes perturbation and all other symbols have standard meaning. All variables and parameters are nondimensional except for $H_{0}$ and $g^{*} ; g^{*}$ is given by

$$
g^{*}=g\left(\left[\bar{\theta}_{t}\right]-\left[\bar{\theta}_{m}\right]\right)\left(\left[\bar{\theta}_{m}\right]-\left[\bar{\theta}_{b}\right]\right)\left[\bar{\theta}_{m}\right]^{-1}\left(\left[\bar{\theta}_{t}\right]-\left[\bar{\theta}_{b}\right]\right)^{-1} .
$$

For lateral walls separated by a distance of $D / L_{0}$, the boundary conditions are

$$
u^{\prime}=0 \text { at } y=0 \text { and } y=D / L_{0} \text {. }
$$

For normal mode stability analysis, we assume wave solutions of the form

$$
\left\{\begin{array}{l}
u^{\prime} \\
v^{\prime} \\
\phi^{\prime}
\end{array}\right\}=\left\{\begin{array}{l}
U(y) \\
i V(y) \\
\Phi(y)
\end{array}\right\} \exp [i k(x-c)],
$$

where $k$ is the zonal wavenumber, $c=c_{r}+i c_{i}$ is the complex phase speed, and capital letters denote complex wave amplitudes. Here, $c_{r}\left(c_{i}\right)$ is the real (imaginary) part of $c$.

Substitution of (4) into (1) leads to the following normal mode stability problem:

$$
\begin{aligned}
k(\bar{u}-c) U-\left(f-\bar{u}_{y}\right) V+k \Phi & =0, \\
k(\bar{u}-c) V-f U-\Phi_{y} & =0, \\
\left(\phi_{0}+\bar{\phi}\right)^{-1}[k(\bar{u}-c) \Phi-f \bar{u} V]+k U+V_{y} & =0 .
\end{aligned}
$$

Here the geostrophic relation for $\pi$ is used in $(5 c)$. The boundary conditions are

$$
V=0 \text { at } y=0 \text { and } y=D / L_{0} .
$$

As the boundary conditions are in $V$, a single equation in $V$ is obtained from (5a)-(5c) (Kuo 1978). The eigenvalue equation for $c$ can be finally written as

$$
\begin{array}{r}
V_{y y+}\left[\left(2 \bar{u}_{y} \sigma+f \bar{u}\right) / \Delta-2 f \bar{u} c_{g}^{-2}\right] V_{y+}\left\{\left(\beta-\bar{u}_{y y}\right) \sigma^{-1}\right. \\
+\left[2\left(f-\bar{u}_{y}\right) \bar{u}_{y}+f\left(f-\bar{u}_{y}\right) \sigma^{-1}-f \bar{u}\left(f \bar{u}+2 \sigma \bar{u}_{y}\right) c_{g}^{-2}\right\} \Delta \\
\left.-\left[\beta \bar{u}+f \bar{u}_{y}+k^{2} \Delta+f\left(f-\bar{u}_{y}\right)\right] c_{g}^{-2}\right\} V=0
\end{array}
$$

where

$$
\sigma=\bar{u}-c ; \quad c_{g}^{2}=\phi_{0}+\bar{\phi} ; \quad \Delta=c_{g}^{2}-\sigma^{2} .
$$

To obtain the equation for $\Phi, U$ from (5a) is substituted in (5c).

$$
k\left(c_{g}^{2}-\sigma^{2}\right) \Phi=\left[\left(f-\bar{u}_{y}\right) c_{g}^{2}-f u \sigma\right] V+c_{g}^{2} \sigma V_{y} .
$$

Here, $U$ is computed from (5a) using $V$ and $\Phi$.

As $\phi_{0 \rightarrow \infty},(5 a)-(5 c)$ reduce to the nondivergent barotropic model. Furthermore, ( $(8)$ implies that $c_{g}^{2} \rightarrow \infty$ and $\Delta \rightarrow \infty$ as $\phi_{0} \rightarrow \infty$, which in turn when used in (7) is reduced to

$$
V_{y y}=\left[\left(\beta-\bar{u}_{y y}\right) \sigma^{-1}-k^{2}\right] V=0 .
$$

Here, $V=k \Psi$ for a nondivergent wave, where $\Psi$ is the amplitude of streamfunction wave; upon substituting in (10), it is reduced to the nondivergent barotropic vorticity equation.

To determine the correctness of formulation of the eigenvalue problem [(7)] and the accuracy of numerical 
computations, the eigenvalues are computed for a large $H_{0}=10^{4} \mathrm{~km}$ and compared with the values obtained from the nondivergent case. The two sets of values are found to be identical up to 2-3 decimal places.

\section{b. Wave kinetic energy equations}

The wave kinetic energy equations are obtained separately for the $u$ and $v$ part of the motion. Let $\mathrm{KIV}_{u}$ $\left(K W_{v}\right)$ denote the zonal average wave kinetic energy per unit mass of $u(v)$. The zonal averaging is done over the wavelength, $\lambda=2 \pi / k$. Using (4), $\mathrm{KW}_{u}\left(\mathrm{KW}_{v}\right)$ can be written in terms of the wave amplitude $U(V)$ as

$$
\mathrm{KIV}_{u}=U U^{*} \exp \left(2 k c_{i} t\right) / 4, \quad \mathrm{KW}_{v}=V V^{*} \exp \left(2 k c_{i} t\right) / 4,
$$

where the asterisk denotes complex conjugate. From (11), we obtain

$$
\left(\mathrm{KWV}_{u}\right)_{t}=k c_{i} U U^{*} / 2, \quad\left(\mathrm{KW}_{v}\right)_{l}=k c_{l} V V^{*} / 2 .
$$

Equation (5a) is multiplied by $-U^{*}$ and the imaginary part of the resulting equation gives

$$
\left(\mathrm{KW}_{u}\right)_{t}=C\left(K_{z}, \mathrm{KW}_{u}\right)-C\left(\mathrm{KW}_{u}, \mathrm{KW}_{v}\right)+\mathrm{GKW}_{u} \text {, }
$$

where $\mathrm{GKW}_{u}$ is the geostrophic zonal average wave kinetic energy, and

$$
\begin{aligned}
K_{z} & =\bar{u}^{2} / 2, \quad C\left(K_{z}, \mathrm{KW}_{u}\right)=\bar{u}_{y} \operatorname{Im}\left(V U^{*}\right) / 2, \\
C\left(\mathrm{KW}_{u}, \mathrm{KW}_{\mathrm{v}}\right) & =f \operatorname{Im}\left(V U^{*}\right) / 2 \\
\text { and } \mathrm{GKW}_{u} & =k \operatorname{Im}\left(U^{*}(\mathrm{I}) / 2 .\right.
\end{aligned}
$$

Here, $K_{2}$ is the kinetic energy of basic flow. The first term on the rhs of (13a), $C\left(K_{z}, \mathrm{KW}_{u}\right)$ denotes the barotropic energy conversion from $K_{z}$ to $\mathrm{KW}_{u}$, due to the wave momentum transport in the meridional direction, $-\operatorname{Im}\left(V U^{*}\right) / 2\left(\overline{u v^{\prime}}\right)$ down the gradient of $\bar{u}$. It is the $u$ part of the wave motion that receives energy from $K_{2}$. The second term denotes the Coriolis transfer of kinetic energy from $u$ to $v$ motion, and the last term represents the generation of $\mathrm{KW}_{u}$ due to the work done by the pressure gradient force in the $x$ direction.

Similarly the equation for $\mathrm{KW}_{v}$ is obtained from (5b). It can be written as follows using the relation $V^{*} \Phi_{y}=$ $\left(V^{*} \Phi\right)_{y}-V_{y}^{*} \Phi$ :

$$
\left(\mathrm{KW}_{v}\right)_{t}=C\left(\mathrm{KW}_{u}, \mathrm{KW}_{v}\right)+\mathrm{GKW}_{\mathrm{v}}-\operatorname{Im}\left(V^{*}(\mathrm{~J})_{y} / 2,\right.
$$

where

$$
\mathrm{GKW}_{v}=\operatorname{Im}\left(V_{y}^{*} \Phi\right) / 2 .
$$

The second term on the rhs of (14a) denotes $\mathrm{KWV}_{v}$ generation due to pressure work in the meridional direction. Here, $V^{*} \Phi / 2$ is the meridional flux of geopotential $\left(\overline{v^{\prime} \phi^{\prime}}\right)$, which transports the wave kinetic energy
$K \mathrm{~W}_{\mathrm{v}}$ along the latitude and vanishes for the quasigeostrophic case. Furthermore, for the nondivergent as well as for the quasigeostrophic wave motion the generation terms $\mathrm{GKW}_{v}$ and $\mathrm{GKW}_{\text {" }}$ are equal and opposite.

The area-averaged eddy kinetic energy $\left(K_{e}\right)$ is obtained upon averaging (13a) and (14a) over the channel and then adding. The flux term vanishes on using the boundary conditions

$$
\left(K_{e}\right)_{t}=C\left(K_{z}, K_{e}\right)+\mathrm{GK}_{e},
$$

where

$$
\begin{aligned}
K_{e} & =\left[\mathrm{KW}_{u}\right]+\left[\mathrm{KW}_{v}\right] ; \\
\mathrm{GK}_{e} & =\left[\mathrm{GKW}_{u}\right]+\left[\mathrm{GKW}_{v}\right] ; \\
C\left(K_{z}, K_{e}\right) & =\left[C\left(K_{z}, \mathrm{KW}_{u}\right)\right] .
\end{aligned}
$$

The growth rate, $k c_{i}$, can also be computed from $\left(K_{e}\right)_{t}$ using the relation

$$
k c_{i}=\left(K_{e}\right)_{i} /\left(2 K_{e}\right)
$$

\section{c. Zonal propagation and growth}

We consider the linear divergent barotropic vorticity equation:

$$
\zeta_{t}^{\prime}=-\bar{u} \zeta_{x}^{\prime}-\left(\beta-\bar{u}_{y y}\right) v^{\prime}-\left(f-\bar{u}_{y}\right) D^{\prime},
$$

where $\zeta^{\prime}$ and $D^{\prime}$ denote relative vorticity and divergence, respectively, and are given by

$$
\zeta^{\prime}=v_{x}^{\prime}-u_{x}^{\prime} \text { and } D^{\prime}=u_{y}^{\prime}+v_{y}^{\prime} .
$$

Using (4) in (17b), we get

$$
\zeta^{\prime}=Z \exp [i k(x-c t)] \text { and } D^{\prime}=i \Delta \exp [i k(x-c t)] \text {, }
$$

where

$$
Z=-\left(k V+U_{y}\right) \text { and } \Delta=k U+V_{y} .
$$

In case $\zeta^{\prime} \neq 0$, it can be easily shown that

$$
c=i k^{-1} \zeta_{l}^{\prime} / \zeta^{\prime}
$$

where

$$
\begin{aligned}
& c_{r}=-k^{-1} \operatorname{Im}\left(\zeta_{t}^{\prime} / \zeta^{\prime}\right), \\
& c_{i}=k^{-1} \operatorname{Re}\left(\zeta_{t}^{\prime} / \zeta^{\prime}\right) .
\end{aligned}
$$

An expression for $\zeta_{i}^{\prime} / \zeta^{\prime}$ is obtained in terms of wave amplitudes from (17a). Then using it in (19b) gives

$$
c_{r}=\bar{u}+k^{-1}\left(\beta-\bar{u}_{y,}\right) \operatorname{Re}(V / Z)+k^{-1}\left(f-\bar{u}_{y}\right) \operatorname{Re}(\Delta / Z) .
$$


The first, second, and third terms on the rhs of (20a) denote wave propagation due to the wave advection by $\bar{u}$, the advection of planetary vorticity, and the wave vorticity generation by the divergence, respectively. Equation (20a) can be written in a computationally more suitable form as

$$
\begin{aligned}
c_{r}= & \bar{u}+k^{-1}\left(\beta-\bar{u}_{y y}\right) \operatorname{Re}\left(V Z^{*}\right) /|Z|^{2}+k^{-1}(f \\
& \left.-\bar{u}_{y}\right) \operatorname{Re}\left(\Delta Z^{*}\right) /|Z|^{2} .
\end{aligned}
$$

Similarly the relation for $c_{i}$ can be obtained as

$$
\begin{aligned}
c_{i}= & k^{-1}\left(\beta-\bar{u}_{y y}\right) \operatorname{Im}\left(V Z^{*}\right) /|Z|^{2} \\
& +k^{-1}\left(f-\bar{u}_{y}\right) \operatorname{Im}\left(\Delta Z^{*}\right) /|Z|^{2} .
\end{aligned}
$$

A large computational error can occur close to the boundaries, as $|Z|$ can be small.

As a special case we consider a nondivergent wave of constant amplitude, superimposed on a uniform zonal flow $\|_{0}$. These assumptions imply that

$$
\bar{u}_{y y}=0 ; \quad U_{y}=0 ; \quad V / Z=-k^{-1} ; \Delta=0 .
$$

Substituting (21) in (20a) gives the Rossby formula for wave phase speed (Rossby 1939):

$$
c_{r}=u_{0}-\beta / k^{2}
$$

\section{Numerical methods}

Equation (7) is written as a set of two first-order equations in $y$ with $V_{1}=V_{y}$ as a new variable. To integrate the equations, we specify $V_{1}=1 / \delta y$ at the south boundary, where $\delta y$ is the grid spacing. The fourth-order accurate Runge-Kutta method is used for the integration.

Here, $c$ for a given wavelength $\lambda(=2 \pi / k)$ is obtained using an iterative scheme. At the $n$th iteration $c^{n}\left(V_{b}\right)$ is the value of $c(V)$ at the north boundary. The increment $\delta c^{n}$ is the smaller absolute root of the following quadratic equation (Kuo 1978):

$$
\begin{aligned}
V_{b}\left(c^{n}+\delta c^{\prime \prime}\right) & =V_{b}\left(c^{n}\right)+V_{b}^{\prime}\left(c^{n}\right) \delta c^{n}+V_{b}^{\prime \prime}\left(c^{n}\right)\left(\delta c^{n}\right)^{2} \\
& =0,
\end{aligned}
$$

where $V_{b}^{\prime}\left(V_{b}^{\prime \prime}\right)$ is the first (second) derivative of $V_{b}$ with respect to $c$ and computed using the center difference scheme. The iteration was terminated when $c^{n+1}-$ $c^{n} \leq \varepsilon$, where $\varepsilon$ is a small prespccified value fixed as $10^{-6}$ in the study.

The first guess of $c$ is obtained from the Howvard semicircle theorem (Howard 1961). Here, $\bar{u}_{y}$ and $\bar{u}_{y y}$ are computed including at boundaries using fourthorder center difference schemes, where requisite values of $\bar{u}$ outside the boundaries are uscd. Furthermore, the computed $\bar{u}_{y}$ and $\bar{u}_{y y}$ are subjected to a 5 -point smoother to suppress the $2 \delta_{y}$ wave (Mishra et al. 1981). The cubic spline is used for interpolation of $\bar{u}$ to the required grid spacing and its midpoint.

\section{Model parameters for VorJ93}

a. $\bar{u}$ and $\left(\beta-\bar{u}_{y y}\right)$ profiles

For zonal averaging the longitude interval from $52.5^{\circ}$ to $22.5^{\circ} \mathrm{WV}$ is chosen, which lies between centers of Bolivian high and South Atlantic trough. Here, $\bar{u}$ is vertically interpolated at the regular pressure interval of 50 $\mathrm{hPa}$ using the cubic spline technique. The vertical averaged $\bar{u}$ in the layer $100-350 \mathrm{hPa}$ is subjected to a 5 -point smoother along the latitude.

Daily profiles of $\pi$ during the prevortex period $1-4$ January are designated as $\mathrm{UJ} 1, \mathrm{UJ} 2, \mathrm{UJ} 3$, and $\mathrm{UJ} 4$, respectively, and are shown in Fig. 1a. An examination of the profiles reveals that a strong shear zone is created around $12^{\circ} \mathrm{S}$ by 4 January mainly due to a progressive northward shift of easterly wind maximum and the development of westerly wind maximum around $7^{\circ} \mathrm{S}$. In the figure, U200 represents the profile at $200 \mathrm{hPa}$ on 4 January. This profile also has the maximum shear around $12^{\circ} \mathrm{S}$. The profiles UJ3 and UJ4 show a sharp linear increase between their easterly and westerly maxims. Hence, the latitudinal separation of wind maxims can be considered as the characteristic length scale $\left(L_{s}\right)$ of the shear zone instead of its half-width, which is appropriate for a hyperbolic tangent profile. An examination of profiles reveals that $L_{s}=1225 \mathrm{~km}$.

The latitude distribution of $\beta-\pi_{y y}$ is shown in Fig. 1b. A strong sign reversal of $\beta-\vec{u}_{y y}$ can be seen around $12^{\circ}$ and $4^{\circ} \mathrm{S}$ in all profiles except for UJ2. This means that $\bar{u}$ prior to the vortex formation satisfies the necessary condition for barotropic instability. MR01 concluded that the mean January 1993 and mean zonal flow during 5-10 January in the upper troposphere satisfy rather weakly the necessary condition for barotropic instability.

The latitudinal channel from $25^{\circ} \mathrm{S}$ to $5^{\circ} \mathrm{N}$ is used for the computation so that its center is close to the latitude of vortex formation. Here, $f_{0}$ and $\beta$ are considered at the middle of the channel, and $U_{0}$ and $L_{0}$ are chosen as $10 \mathrm{~m} \mathrm{~s}^{-1}$ and $10^{6} \mathrm{~m}$, respectively.

\section{b. $g^{*}$ and $H_{0}$}

The reduced gravity $g^{*}$ is computed from the mean and vertically averaged $\theta$ for January 1993 in the layers $350-1000,100-350$, and $10-100 \mathrm{hPa}$ over the area $25^{\circ} \mathrm{S}-$ $5^{\circ} \mathrm{N}, 52.5^{\circ}-22.5^{\circ} \mathrm{W}$. The computed value of $g^{*}$ is found to be $0.8 \mathrm{~m} \mathrm{~s}^{-2}$. 
(a)
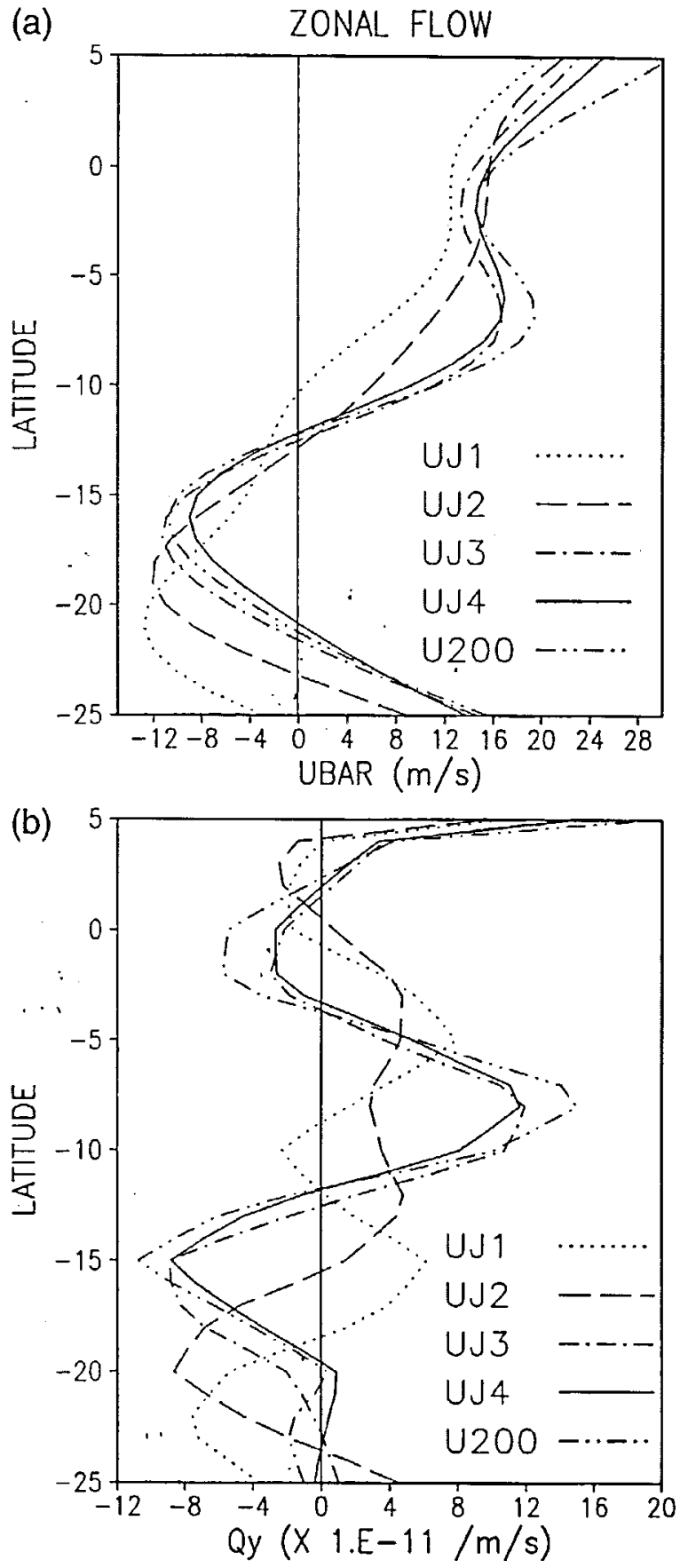

FIG. 1. Latitudinal distributions of zonally $\left(52.5^{\circ}-22.5^{\circ} \mathrm{W}\right)$ and vertically $(100-350 \mathrm{hPa})$ averaged daily (a) zonal wind $\left(\mathrm{m} \mathrm{s}^{-1}\right)$, and (b) $\beta-\pi_{y y}\left(10^{-11} \mathrm{~m}^{-1} \mathrm{~s}^{-1}\right)$ during $1-4$ Jan 1993 and at the 200-hPa level for 4 Jan 1993.

The middle layer is considered as an incompressible fluid with a density at the vertical average pressure and temperature. Here, $H_{0}$ is defined as the depth over which a pressure falls by $250 \mathrm{hPa}$. The computed value of $H_{0}$ is $7 \mathrm{~km}$, which is close to the scale height. 'The Rossby deformation radius, $L_{R}$, which is generally used as the length scale for midlatitude synoptic-scale motion, is computed from the relation (Pedlosky 1987)

$$
L_{R}=\left(g^{*} H_{0}\right)^{1 / 2} / f_{0} .
$$

The computed value of $L_{R}$ is $3000 \mathrm{~km}$.

\section{Instability of zonal flow during the prevortex period of VorJ93}

Based on numerical experiments, $\delta y=1^{\circ}(111.2 \mathrm{~km})$ is considered adequate for the computations. Furthermore, wavelength at the interval $\delta \lambda=500(1000) \mathrm{km}$ is specified in the range $2500-6000(6000-10000) \mathrm{km}$. For each $\lambda$, the fastest-growing and fastest-converging solution was selected. Subsequently, its continuity with the previous lower $\lambda$ solution with regards to its amplitude distribution and phase speed was examined. If found necessary, the next-fastest-growing solution was picked up. Initially, the gross fastest-growing wave in the complete range of $\lambda$ is determined; subsequently to obtain the more accurate value, $\lambda$ around the gross value is sampled at the shorter interval of $\delta \lambda=250 \mathrm{~km}$.

\section{a. Preferred wavelength, its growth rate, and phase speed}

The daily growth rate $\left(k c_{i}\right)$ and phase speed $\left(c_{r}\right)$ spectra as a function of $\lambda$ for the prevortex period are presented in Figs. 2a and 2b, respectively. The spectra for the profile $\mathrm{U} 200$ are also included in the figures. It can be seen from $k c_{i}$ spectra that $\bar{l}$ has progressively became more and more unstable and developed a sharp peak with time as it approaches the day of vortex formation. The fastest-growing wave for UJ4 has $\lambda=4000$ $\mathrm{km}$ and $k c_{i}=0.554$ day $^{-1}$, which implies an $e$-folding time of 1.8 days. Hereafter, the fastest-growing wave associated with $\mathrm{UJ} 4$ will be called the preferred wave if not mentioned otherwise. MRG estimated the wavelength as $3000 \mathrm{~km}$ for VorJ93 from its horizontal distributions of bandpass wind and geopotential. We will present a possible reason, while discussing the horizontal structure subsequently, for why the observed wavelength of VorJ93 is less than the average value for the vortex. The zonal scale of the preferred wave can be taken as $\lambda / \pi$ (Mishra et al. 1981), which is equal to 1270 $\mathrm{km}$. This value is very close to $L_{s}$ but much smaller than $L_{R}$. MRG also reached the same conclusion regarding the relation between the length scale of large-scale flow and embedded vortex. Here, $c_{r}=0.73 \mathrm{~m} \mathrm{~s}^{-1}$, which is small and in a good agreement with the observation that the vortex remained almost stationary. 
(a)

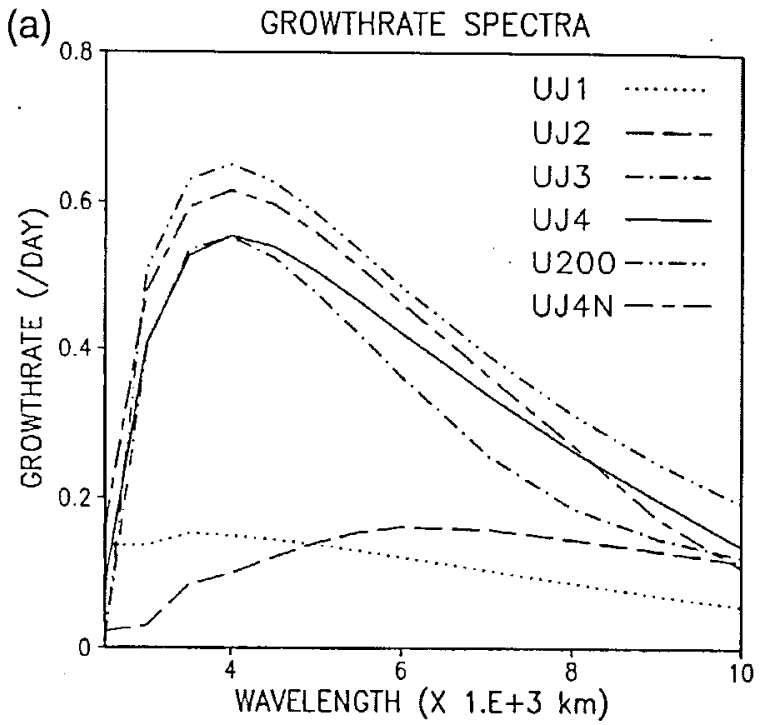

(b)
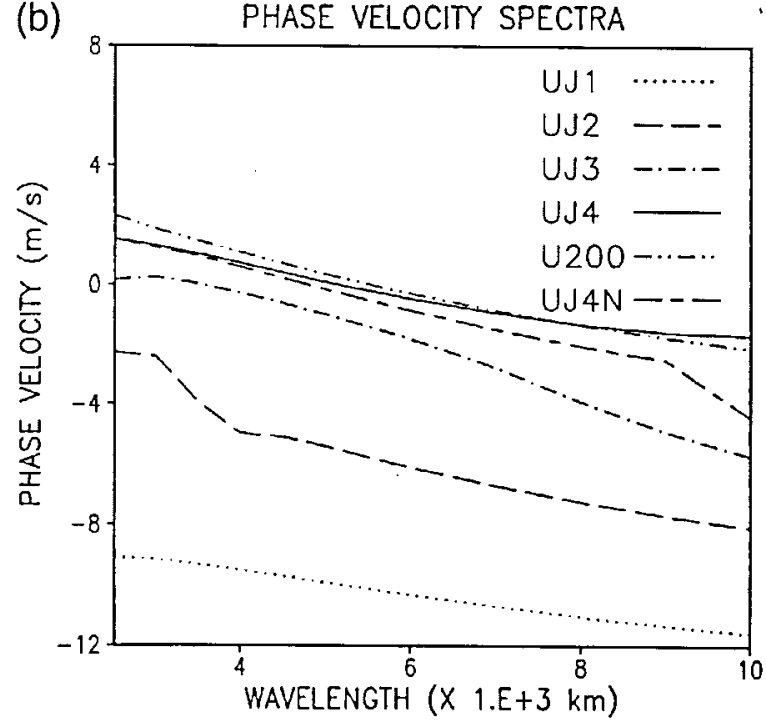

Fig. 2. (a) Growth rate $\left(\right.$ day $\left.^{-1}\right)$ and (b) phase speed $\left(\mathrm{m} \mathrm{s}^{-1}\right)$ as a function of wavelength $\left(10^{3} \mathrm{~km}\right)$ for the UJ1, UJ2, UJ3, UJ4, and $\mathrm{U} 200$ profiles. UJ4N spectra are for the nondivergent case of the UJ4 profile.

The $k c_{i}$ and $c_{r}$ spectra for $\bar{u}$ profiles at 300-, 200-, and 100-hPa levels have also been computed but not presented, except for U200. A comparison of these spectra with the layer spectra (Fig. 2a) reveals that while the preferred $\lambda$ remained unchanged, $\bar{l}$ at 300 and $200 \mathrm{hPa}$ is more unstable compare to the layer. The largest growth rate for $\mathrm{U} 200$ is $0.651 \mathrm{day}^{-1}$. Here, $\bar{u}$ at $100 \mathrm{hPa}$ is marginally unstable and preferred wavelengths lie in the range $6000-7000 \mathrm{~km}$. A southward (northward) shift of the channel leads to an increase (decrease) of growth rate without any change in the preferred wave- length and the location of wave amplitude maximum. This can be understood in terms of decrease (increase) of $\beta$, which implies a decrease (increase) of its stabilization effect.

The nondivergent preferred $\lambda$ for UJ4 is $4000 \mathrm{~km}$ with a growth rate of $0.616 \mathrm{day}^{-1}$. Hence divergence reduces the preferred growth rate. The $k c_{i}$ and $c_{r}$ spectra are also computed after neglecting the effect of vertical stratification, $g^{*}=g$ (not presented). It is inferred that the stratification stabilizes (destabilizes) the flow for $\lambda<(>) 8000 \mathrm{~km}$. Furthermore, the stabilization (destabilization) effect decreases (increases) with the increase of $\lambda$. The stratification has no effect on the preferred $\lambda$. However, it induces a very small westivard component of movement. These results are as expected and confirmed that the unstable waves obtained in the study are physical, not numerical, modes.

No significant barotropic unstable mode is found for the mean $\bar{u}$ for January 1993, even though the number of vortex days is quite high. Furthermore, $\bar{u}$ immediately after the vortex formation is very weakly unstable (not presented). These results are understandable as the mean flow of January, and the vortex period satisfies very weakly the necessary condition of barotropic instability (MR01; MRG).

\section{b. Structure of the preferred wave,}

For a better comparison of the preferred wave with the observed vortex, the latter was isolated from observed winds at 1200 UTC at $200 \mathrm{hPa}$ on 6 January after subjecting them to the bandpass smoother. To eliminate the generation of boundary errors the wind data along the complete latitude circle are used. Day 2 of VorJ93 is selected, as the system is fully developed by then. In Fig. 3a, the bandpass streamlines are presented. A cyclonic center can be easily located at $9^{\circ} \mathrm{S}$, $32.5^{\circ} \mathrm{W}$ and an anticyclonic center is to its west. A system of cyclonic and anticyclonic circulation can be considered to be a wave of wavelength around $3000 \mathrm{~km}$. To the east of the cyclonic center a deep intrusion from the north can be seen. It might have pushed the cyclonic center toward the anticyclonic center along the longitude. This may be one possible reason why the wavelength of VorJ93 is less than the average value. This also partially accounts for the large difference between wavelengths of preferred wave and the observed vortex VorJ93. The streamline patterns exhibit a strong southeast to northwest tilt.

For normalization of the preferred wave, the $|V|$ maximum is fixed so that the maximum transport associated with it is equal to that of the observed transport computed from the bandpass $u$ and $v$ at $200 \mathrm{hPa}$ on 6 January. Hence the $|V|$ maximum value is $6.7 \mathrm{~m} \mathrm{~s}^{-1}$. 

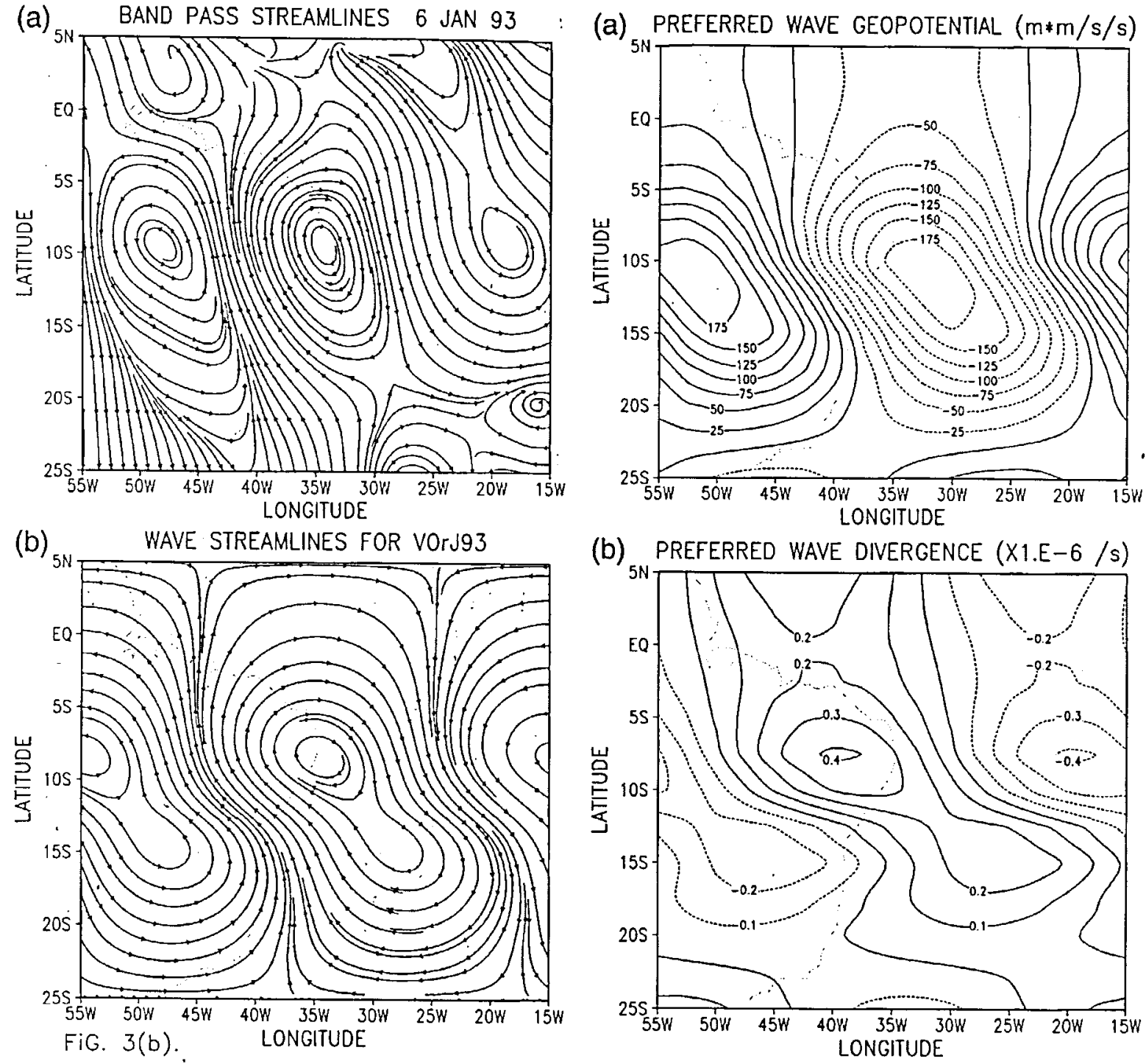

Fig. 4. Horizontal distribution of (a) geopotential $\left(\mathrm{m}^{2} \mathrm{~s}^{-2}\right)$ and

Fig. 3. Horizontal distribution of (a) bandpass streamlines at $200 \mathrm{hPa}$ on 6 Jan 1993 and (b) strcamlines for the normalized primitive equation preferred wave of the UJ4 profilc.

This value is very close to the maximum value of $u$-wave amplitude obtained by MRG. The streamlines for the preferred wave are presented in Fig. $3 b$. It is seen from the figure that the trough and ridge tilt strongly in the southeast-northwest direction and the center of cyclonic circulation is located very close to $9^{\circ} \mathrm{S}$. Both of these features are in agreement with the observed vortex. Southeast-northwest tilt is an average feature observed in cyclonic vortices (Kousky and Gan 1981; Kayano et al. 1997; MRG). The maximum intensity of wave in terms of its relative vorticity occurs where the maximum of $\beta-\bar{l}_{y y}$ is located, which is to the north of (b) divergence $\left(10^{-6} \mathrm{~s}^{-1}\right)$ for the normalized primitive equation preferred wave of the UJ4 profile. Contour intervals are $25 \mathrm{~m}^{2} \mathrm{~s}^{-2}$ and $0.1 \times 10^{-6} \mathrm{~s}^{-1}$ for geopotential and divergence, respectively.

maximum shear. The cyclonic center of the nondivergent wave is also located very close to $9^{\circ} \mathrm{S}$ (not presented).

A comparison of the geopotential (Fig. 4a) and streamline distributions indicates that the low lies about $3^{\circ}$ south of the cyclonic center, a feature noted in many earlier instability studies for tropical disturbances (Mak and Kao 1982; Mishra et al. 1985). Furthermore, the contours exhibit a strong southeast-northwest tilt similar to streamlines. The latitudinal half-width of the geopotential distribution is about $12^{\circ}$, which can be con- 
sidered as the meridional scale of the wave. This is in good agreement with the meridional scalc of $1275 \mathrm{~km}$ obtained by MRG for VorJ93. The meridional and zonal scales of wave are comparable. The convergence is located in the southwest sector of wave (Fig. 4b) as noted by $M R G$.

\section{c. Momentum transport}

The wave momentum transport $\left(\overline{u^{\prime} v^{\prime}}\right)$ associated with the normalized preferred wave is shown in Fig. 5. The westerly momentum transports are southward, which is consistent with the pronounced southeastnorthwest tilt of the wave. It is mainly confined to the latitude belt corresponding to the basic-state shear zone; the latitude of maximum $\overline{u^{\prime} v^{\prime}}$ nearly coincides with that of the maximum shear. The strong transport occurs in the very narrow latitude belt of $5^{\circ}$ around $12^{\circ} \mathrm{S}$, which is the half-width of the profile. The transport is against the shear of $\bar{u}$ (see Fig. 1a). Furthermore, the convergence (divergence) of westerly wave momentum occurs in the basic-state easterly (westerly) zone. This situation is favorable to reduce the shear of $\bar{u}$ and to transfer kinetic energy from $\pi$ to the wave. To isolate the role of divergence, the profile for the nondivergent case is also included in the figure. The nondivergent wave is also normalized such that the $|V|$ maximum is $6.7 \mathrm{~m} \mathrm{~s}^{-1}$. Practically no difference can be noted between the divergent and nondivergent profiles. It seems that the divergence has no significant influence on the distribution of momentum transport.

The observed momentum transport computed from the bandpass $u$ and $v$ is also presented in the figure. It can be said that the transport by the wave is very close to the observed one except that the former is shifted to south by $3^{\circ}$. A closer examination of Fig. 3a (Fig. 3b) reveals that the observed (wave) tilt is more to the north (south) than to the south (north) of the center. This provides a possible explanation for the southward shift of transport distribution relative to the observed one.

\section{d. Energetics of the preferred wave}

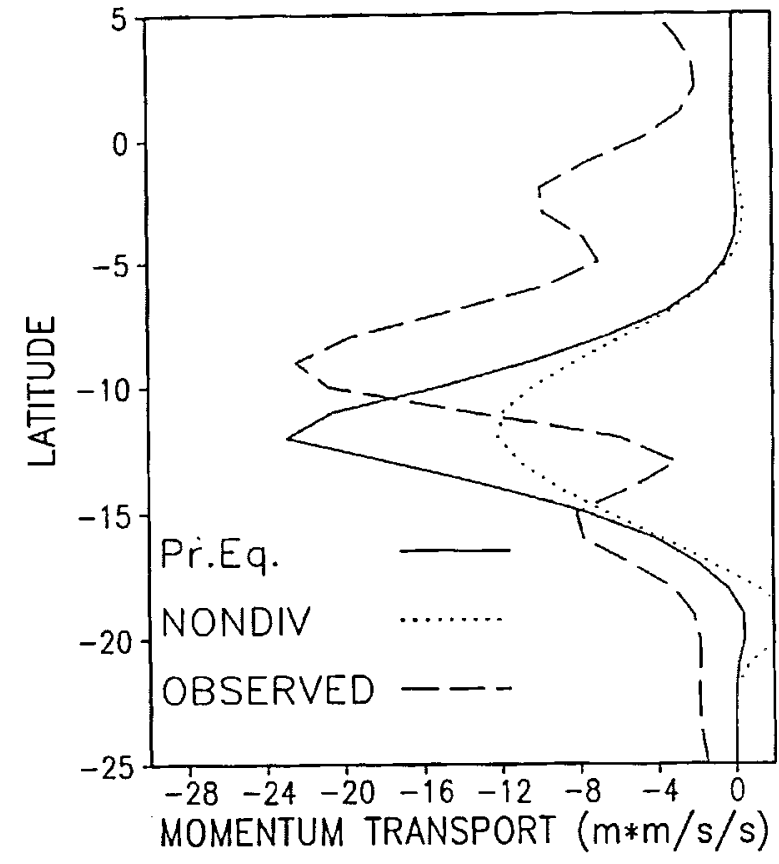

FıG. 5. Latitudinal distributions of zonal averaged momentum transport, $\overline{u^{\prime} v^{\prime}}\left(\mathrm{m}^{2} \mathrm{~s}^{-2}\right)$, associated with the normalized primitive equation (solid) and nondivergent (dotted) preferred waves for the UJ4 profile. The observed momentum transport profile (dashed) is computed using bandpass winds. For the preferred waves zonal averaging is done over their wavelength while for observed from $55^{\circ}$ to $27.5^{\circ} \mathrm{W}$.

For the wave $v$-motion, the work done by pressure force is responsible for its growth, while the Coriolis transfer of energy from $v$ to $u$ motion acts as a sink in the shear zone (Fig. 6b). The excess wave kinetic cnergy in the shear zone is transported away by $\overline{v^{\prime} \phi^{\prime}}$. The intensification of the $v$-motion beyond the shear zone is due to the convergence of $\overline{v^{\prime} \phi^{\prime}}$, which is stronger than the decay due to $\mathrm{GKW}_{v}$ Since $\overline{v^{\prime} \phi^{\prime}}$ are significantly large, the unstable wave cannot be treated as the geostrophic one. On the other hand, GKW and GKW are nearly equal and opposite, and the wave can be approximated as the nondivergent one. As expected, the latitudes of maximum wave kinetic energy and the low are close to each other.

The latitude averaged energy cycle associated with the preferred wave is shown in Fig. 7. The growth of wave $u$-motion is not only due to the kinetic energy received from basic flow but equally from its $v$-motion due to the Coriolis transfer. The $v$-motion is intensified as a result of the work done by the pressure force. The $u$-motion is losing energy as it is doing work against the pressure force. Overall, the work done by the pressure force (divergence effect) acts as a very small sink for $K_{e}$ 
(a)

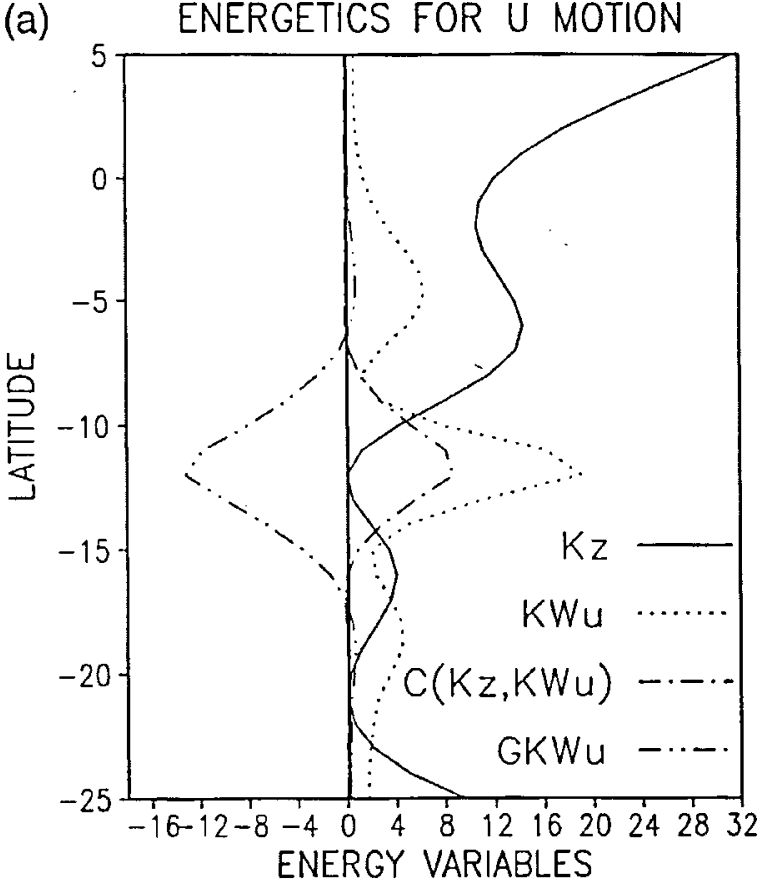

(b)

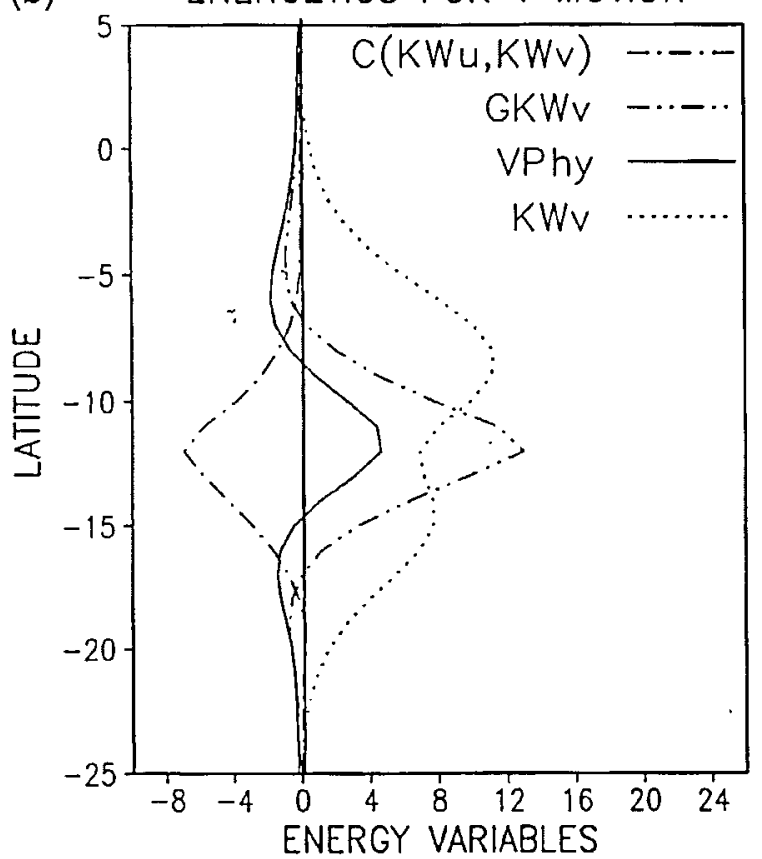

FIG. 6. Latitudinal distributions of energy components $\left(\mathrm{m}^{2} \mathrm{~s}^{-2}\right)$, conversions $\left(10^{-4} \mathrm{~m}^{2} \mathrm{~s}^{-3}\right)$, and generations $\left(10^{-4} \mathrm{~m}^{2} \mathrm{~s}^{-3}\right)$ due to work done by pressure force associated with ithe normalized primitive equation preferred wave (a) 11 - and (b) $v$-motion. Vphy $\left(10^{-4} \mathrm{~m}^{2} \mathrm{~s}^{-3}\right)$ in (b) is the divergence of zonal averaged meridional flux of geopotential, $\overline{v^{\prime} \phi^{\prime}}$, and $K_{z}\left(10 \mathrm{~m}^{2} \mathrm{~s}^{-2}\right)$ in (a) is the kinetic energy of basic zonal flow.

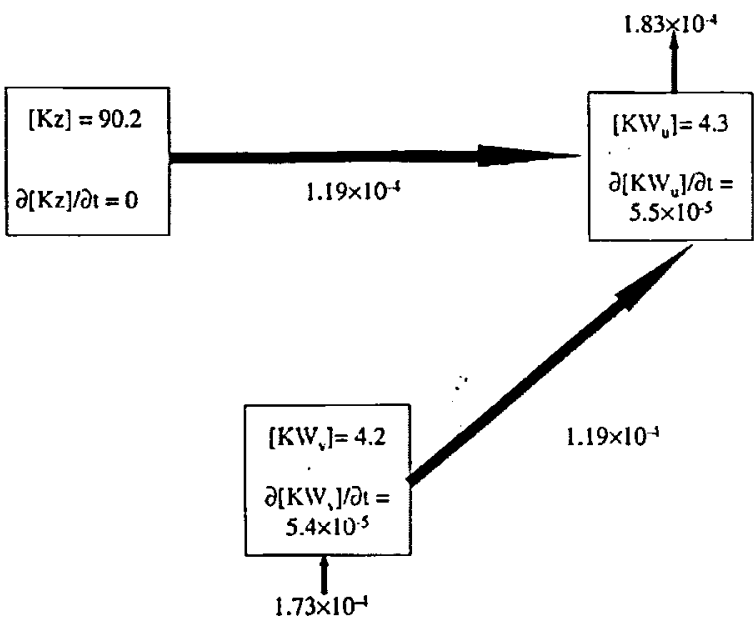

FIG. 7. Barotropic energy cycle for the normalized primitive equation wave for the UJ4 profile. Energy components $K_{z}$, $\left[\mathrm{KWV}_{\mathrm{u}}\right]$, and $\left[\mathrm{KW} \mathrm{V}_{\mathrm{v}}\right]$ are in $\mathrm{m}^{2} \mathrm{~s}^{-2}$ and energy conversions; tendencies and generations are in $\mathrm{m}^{2} \mathrm{~s}^{-3}$. All quantities are averaged over the latitude interval $25^{\circ} \mathrm{S}-5^{\circ} \mathrm{N}$.

and the conversion as the main source for its growth. The energy cycle for $K_{e}$ may open to an erroneous conclusion that it is energy transfer from $K_{z}$ that is responsible for the growth of both $u$ - and $v$-motion of the wave and it is approximately geostrophic. It may be mentioned that the growth rate computed using time tendency of $K_{c}$ is in close agreement to the value obtained in the study.

MR01 computed vertically integrated mean barotropic energy conversion in the layer $100-500 \mathrm{hPa}$ for VorJ93 as $0.63 \mathrm{~W} \mathrm{~m}^{-2}$. This value includes a significant positive contribution from the eddy $\mathrm{v}$ momentum transport, which is absent in the instability problem of $\bar{u}$. We assume that the energy conversion value obtained in the study is valid as well for the layer 100-500 hPa. On the basis of this assumption, the vertically integrated barotropic energy conversion is computed for the preferred wave as $0.48 \mathrm{~W} \mathrm{~m}^{-2}$, which is comparable to the observed value mentioned above.

\section{e. Influence of divergence on the preferred wave}

The contribution of $\beta-\bar{u}_{y y}$ and divergence terms to $c_{i}$ are computed from (20c) for the preferred wave. Let $c_{i \beta}\left(c_{i d}\right)$ denote the imaginary part of $c$, due to the $\beta-$ $\bar{u}_{y y}$ (divergence). The channel-averaged value for the divergent (nondivergent) wave is $c_{i \beta}=4.44(4.46) \mathrm{m} \mathrm{s}^{-1}$ and $c_{i d}=-0.40(0) \mathrm{m} \mathrm{s}^{-1}$. It is evident that the divergence stabilizes shear flow and reduces the preferred wave growth by around $10 \%$. The stabilization of waves is predominately accounted for by the negative work done by pressure force in presence of divergence. 
Each of the terms on the rhs of (20b) is computed separately, in order to study the preferred wave movement and the role of divergence. It is noted that advection by $\overline{\|}$ moves the wave eastward, which is nearly balanced by westward propagation due to the planetary vorticity advection and divergence. The contribution of divergence toward the westward movement is significant, which is about $20 \%$ of the planetary vorticity advection. The divergence inducing westward motion to the preferred wave is physically understandable as the region of convergence, which generates cyclonic vorticity, is located to the southwest of the cyclonic center (see Fig. 4b).

It is justified to conclude on the basis of the above discussion that the divergence effect on the growth and movement of the unstable barotropic wave is similar to the $\beta$ effect.

\section{Model parameters for VorN01}

Daily $\bar{u}$ profiles in the layer $100-350 \mathrm{hPa}$ are computed during the prevortex period and on 13 November for VorN01. The area $22.5^{\circ} \mathrm{S}-7.5^{\circ} \mathrm{N}, 52.5^{\circ}-22.5^{\circ} \mathrm{W}$ is selected for computations. Other parameters are similar to that of VorJ93. The latitudinal distributions of $\bar{u}$ are designated as UN10, UN11, UN12, and UN13 for 10 , 11,12 , and 13 November, respectively, and are presented in Fig. 8a. It can be noted that a shear zone developed quitc fast during the prevortex period. The shear zone is not seen on 10 November; it is strongest on 12 November around $8.5^{\circ} \mathrm{S}$ and shows the sign of weakening on the day of formation of the vortex. A comparison of Fig. 1a and Fig. $8 \mathrm{a}$ indicates that features associated with the development of shear zone for VorJ93 and VorN01 are similar, but the latter is shifted northward with respect to the former and it is weaker. Here, $L_{s}=900 \mathrm{~km}$, which is less than that of VorJ93.

All profiles satisfy the necessary condition for the barotropic instability (Fig. 8 b). The profile UN10 satisfies the condition very weakly and close to the south boundary. Furthermore, $\beta-i_{i y}$, the profile for UN10, is such that it can never satisfy the necessary and sufficient condition for the instability, as wave amplitude is largest around the middle of the channel. The variation of $\beta-\bar{u}_{y y}$ across the shear zone is about $1.44 \times 10^{-10}$ $\mathrm{m}^{-1} \mathrm{~s}^{-1}$, which is much smaller than the value $2.1 \times$ $10^{-10} \mathrm{~m}^{-1} \mathrm{~s}^{-1}$ for VorJ93. The variation of $\beta-\bar{u}_{y y}$ indicates that $\pi$ for VorN01 is likely to be less unstable than that of VorJ93.

\section{Instability of zonal flow during the prevortex period of VorN01}

Here, we present, in brief, the main results for VorN01; $k c_{l}$ and $c_{r}$ spectra for UN11, UN12, and UN13
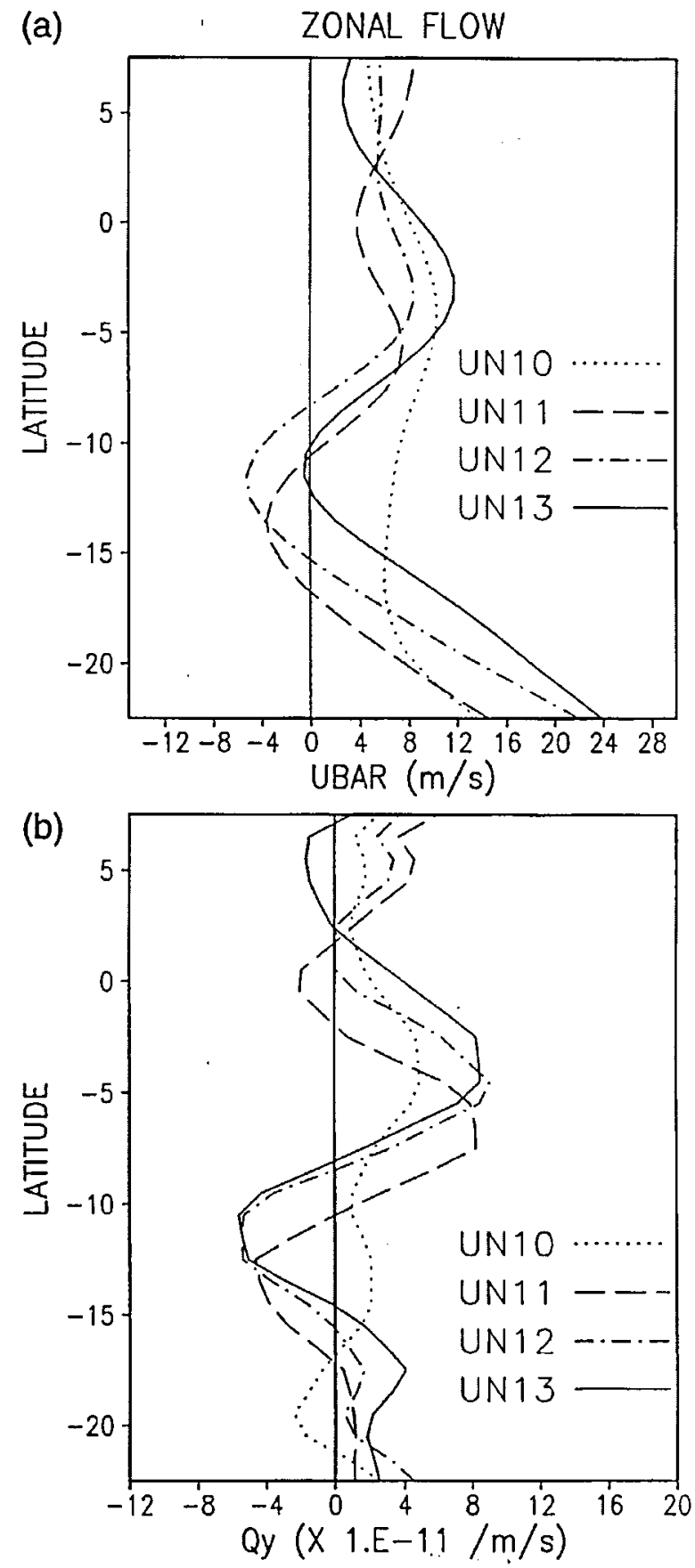

FIG. 8. Same as in Fig. 1, except for the period 10-13 Nov 2001.

are shown in Figs. 9a and 9b, respectively. As expected no unstable mode is found for UN10. The preferred wave for UN12 has $k c_{i}=0.311 \mathrm{day}^{-1}, c_{r}=-0.658$ $\mathrm{m} \mathrm{s}^{-1}$ and $\lambda=3000 \mathrm{~km}$. The preferred wavelength is in complete agreement with the observed value, which has been mentioned in section $2 \mathrm{~b}$. It may be noted that the 


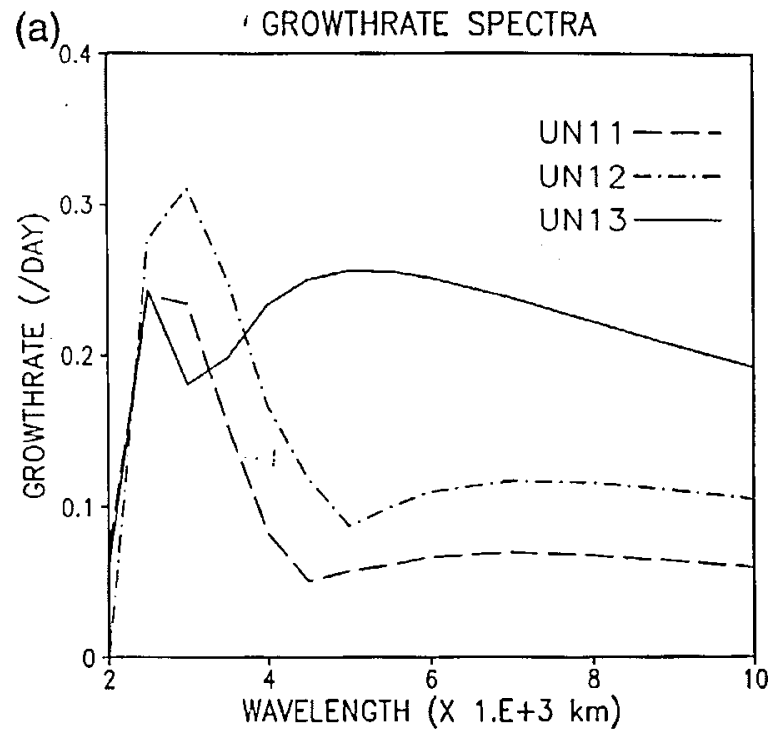

(a) BAND PASS STREAMLINES 13 NOV 01

(b)

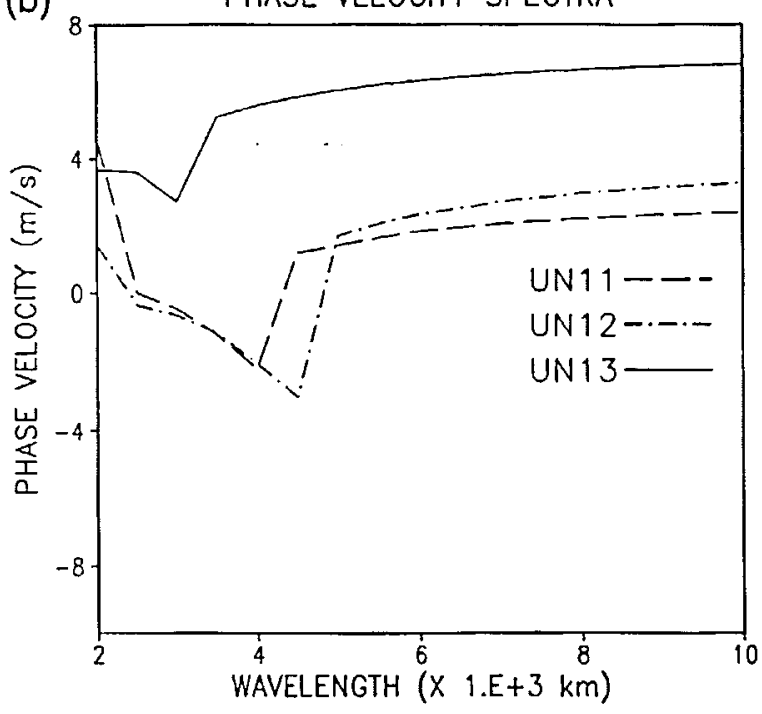

Fig. 9. Same as in Fig. 2, except for profiles UN11, UN12, and UN13.

ratio of largest growth rate to the change of dynamical parameter $\beta-\bar{u}_{y y}$ across the shear zone is nearly the same for the two cases considered in the study. Hence, it can be said that it is shear zone that controls to a large extent the growth of vortices. The zonal scale of the preferred wave is $955 \mathrm{~km}$, which is close to $L_{s}$. A similar relation between the wave zonal scale and $L_{s}$ has been noted for VorJ93. The $k c_{i}$ spectrum for UN13 has a sharp peak at $2500 \mathrm{~km}$ and a flat peak at $4500 \mathrm{~km}$ of nearly same values $\left(0.243 \mathrm{day}^{-1}\right)$. The real part of the phase speed $c_{r}=3.5 \mathrm{~m} \mathrm{~s}^{-1}$ for the smaller wave is very

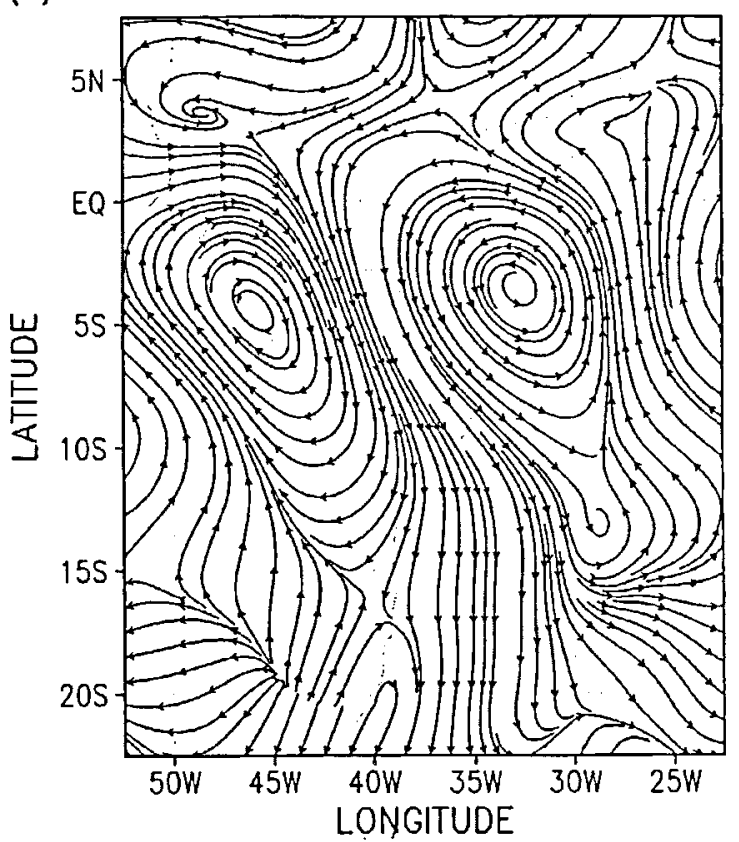

(b) WAVE STREAMLINES FOR VOrNO1

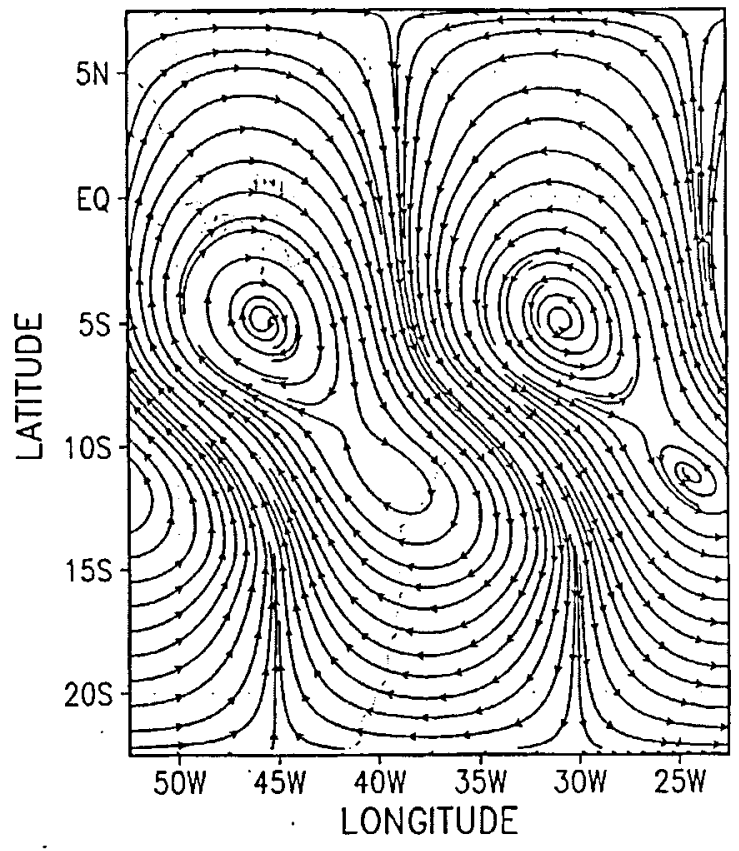

Fig. 10. Same as in Fig. 3, except for (a) 13 Nov 2001 and (b) the preferred wave of the UN12 profile.

close to the observed speed of the vortex during 13-14 November.

The bandpass streamlines at $200 \mathrm{hPa}$ for 13 November are presented in Fig. 10a. A pair of well-developed 
intense cyclonic and anticyclonic centers can be seen. The cyclonic center is located at $5^{\circ} \mathrm{S}, 45^{\circ} \mathrm{W}$. The streamlines associated with the vortex exhibit a strong southeast to northwest tilt. The streamlines for normalized the preferred wave are shown in Fig. 10b. For the normalization, the $|V|$ maximum is fixed at the same value as used for VorJ93. The cyclonic center is located at $5^{\circ} \mathrm{S}$, which is in complete agreement with the observed location. Furthermore, the center is located to the north of maximum shear and coincides with the latitude of maximum $\beta-\vec{u}_{y y}$, a feature common with VorJ93. It is seen from the figure that the strong southeastnorthwest tilt is in agreement with the observations.

Here, $\overline{u^{\prime} v^{\prime}}$ is southward throughout the belt but concentrated in a narrow zone around its peak value of 18 $\mathrm{m}^{2} \mathrm{~s}^{-2}$ at $8.5^{\circ} \mathrm{S}$, which coincides with the latitude of maximum shear (not presented). A similar relation between latitudes of $\overline{u^{\prime} v^{\prime}}$ and the shear maxima has been found for VorJ93. The southward $\overline{u^{\prime} v^{\prime}}$ is consistent with the tilt of the wave. Furthermore, $\overline{u^{\prime} v^{\prime}}$ is against the shear of $\pi$, a situation favorable for the growth of the wave by the barotropic process.

The energy cycle associated with the preferred wave is computed but not presented. The cycle is the same as that of VorJ93 except that it is weak; the Coriolis transfer is stronger than the barotropic energy conversion. Since $\mathrm{GKW}_{u}$ and $\mathrm{GKW}_{v}$ exactly balance each other, the wave can be treated to a good degree of approximation as a nondivergent.

\section{Discussion and conclusions}

The divergent barotropic stability of daily $\overline{\|}$ profiles in the layer 100-350 hPa before and after the formation of vortices VorJ93 and VorN01 is examined. Before the formation of vortices, $\bar{u}$ becomes progressively unstable with the passage of time. It is shown that the zonal and meridional scales of the fastest-growing wave are in good agreement with the observations. Furthermore, these scales are related to the shear zone but not to the Rossby deformation radius. This indicates the dominating role of barotropic dynamics and the controlling influence of shear zone in the vortex development.

A close agreement is found between the computed horizontal structures, momentum transports, and barotropic energy conversions associated with fastestgrowing barotropic, normalized normal mode and the observed cyclonic vortex. It is shown that the barotropic energy conversion (work done by pressure force) is the energy source for the growth of wave $u$ - $(v)$ motion, the wave amplitude, and $\overline{\|^{\prime} v^{\prime}}$ and $\overline{v^{\prime} \phi^{\prime}}$ are basically confined to the shear zone. The results of the study suggest that the barotropic instability of the shear zone can excite observed upper-tropospheric cyclonic vortices in the vicinity of northeast Brazil.

On the basis of results obtained here and available in our earlier studies (MRG; MR01), we arrived at the following possible scenario regarding the formation of cyclonic vortices and their subsequent development. In a short span of 2-3 days, before the vortex formation, a barotropically unstable, strong latitudinal shear zone developed in the region between the upper-tropospheric large-scale Bolivian high and South Atlantic trough. The development of shear zone can be attributed to the intensification, the favorable relative movement and orientation of the Bolivian high and its associated ridge, and the Atlantic trough. The barotropic instability of the shear zone can trigger the vortex formation. The sharp iveakening of the shear zone and almost comiplete release of its instability on some cases are characteristics associated with the vortex formation. Thus the vortex formation may be considered as an event or an episode. The southeast-northwest tilt of the wave implies a downgradient transport of wave momentum, such that the divergence (convergence) of westerly momentum is in the region of large-scale westerly (easterly) winds. Furthermore, this situation is favorable for a transfer of kinetic energy from the shear zone to the vortex, which leads to a further weakening of the former and an intensification of the latter, cven though the basic flow is no longer unstable. The number of vortex days in a month may be large, but the number of days when the large-scale flow is unstable is small. It is understandable that the signature of barotropic instability in connection with the formation of vortices cannot be clearly seen in the upper-tropospheric monthly mean $\overline{\|}$ of January 1993 and November 2001. In some cases a partial release of barotropic instability occurs with the vortex formation. This mode of vortex formation needs further investigation. It will be rather difficult to arrive at a scenario as presented above on the basis of an idealized or a mean $\bar{u}$ profile. It can be concluded that the stability analyses of daily observed profiles are likely to provide a better insight on the genesis of tropical disturbances than that obtained from an idealized or a mean $\bar{\pi}$.

It is not intended to discard the possible role of baroclinic process in the initial scale selection, in horizontal movement, and in the further development of the vortex. We have not considered the role of zonal-wave interaction in the development of the vortex, which seems to be quite significant as pointed out by MRG. A nonlinear stability study can bring the preferred unstable mode still closer to reality. It is well established that the convective activity takes place away from the center and along the periphery in the western sector of 
vortex. The convection can play an important role in the maintenance of vortex, which is ignored in the study. The stability analysis of latitude-varying $\pi$ cannot provide a proper basis to explain the preferred longitude for the occurrence of the vortex. For this purpose a stability analysis of zonally varying basic flow is sug. gested as a future study.

Acknowledgments. We thank Dr. M. A. Gan for numerous scientific discussions regarding the observational aspects of the cyclonic vortex. We are grateful to Dr. G. C. Asnani for his critical scientific remarks on the manuscript. Thanks are also due to Dr. J. P. R. Fernandez for his help in graphics and computations. We thank Dr. Maria Assunçāo F. Silva Dias for her interest in this work and for her support. The first author is grateful to Fundação de Amparo a Pesquisa do Estado de São Paulo (FAPESP) for providing a fellowship during his stay at the INPE (Brazil).

\section{REFERENCES}

Howard, L. N., 1961: Note on a paper of John IV. Miles. J. Flhid Mech., 10, 509-512.

INPE, 1993: Climate and synoptic aspects of Brazil-Atmospheric perturbation (in Portuguese). Climanalise, Vol. 8, No. 1, INPE/CPTEC, $42 \mathrm{pp}$. (Available from Instituo Nacional De Pesuisas Espaciais, CPTEC, Rod Presidente Dutra, Km 40C.P. 01, 12630-000-Cachoerira Paulista-SP, Brazil.]

- 2001: Climate and synoptic aspects of Brazil-Atmospheric perturbation (in Portuguese). Climanalise, Vol. 16, No. 11, INPE/CPTEC, 43 pp. [Available from Instituo Nacional De Pesuisas Espaciais, CPTEC, Rod Presidente Dutra, Km 40 C.P. 01, 12630-000-Cachoerira Paulista-SP, Brazil.]

Kayano, M. T., N. J. Ferreira, and M. C. V. Ramircz, 1997: Summer circulation patterns related to the upper tropospheric vortices over the tropical south Atlantic. Meteor. Atmos. Plys., 64, 203-213.
Kousky, V. E., and M. A. Gan, 1981: Upper tropospheric cyclonic vortices in tropical South Atlantic. Tellus, 33, 538-550.

Kuo, H. L., 1949: Dynamic instability of two-dimensional nondivergent flow in a barotropic atmosphere. J. Meteor., 6, 105122.

-1, 1973: Dynamics of quasi-geostrophic flows and instability theory. Advances in Applied Mechanics, Vol. 13, Academic Press, 248-330.

- 1978: A two-layer model study of the combined barotropic and baroclinic instability in the tropics. J. Atmos. Sci, 35, $1840-1860$.

Mak, M. K., and C.-Y. J. Kao, 1982: An instability study of the onset vortex of the southwest monsoon. Tellits, 34, 358-368.

Mishra, S. K., and V. B. Rao, 2001: The energetics of an upper tropospheric cyclonic vortex over north-east Brazil. Quart. J. Roj: Meteor. Soc., 127, 2329-2351.

- D. Subrahmanyam, and M. K. Tandon, 1981: Divergent barotropic instability of the tropical asymmetric easterly jet. J. Atmos. Sci., 38, 2161-2171.

-, M. D. Patwardhan, and L. George, 1985: A primitive equation barotropic instability study of the monsoon onset vortex, 1979. Quart. J. Roy. Meteor. Soc., 111, 427-444.

- - V. B. Rao, and M. A. Gan, 2001: Structure and evolution of the large-scale flow and an embedded upper-tropospheric cyclonic vortex over northeast Brazil. Mon. Wea. Rev, 129, 1673-1688.

Pedlosky, J., 1987: Geoplysical Fluid Dynamics. Springer-Verlag, $710 \mathrm{pp}$.

Ramirez, M. C. V., M. T. Kayano, and N. J. Ferreira, 1999: Statistical analysis of upper tropospheric vortices in the vicinity of northeast Brazil during the 1980-1989 period. Atmosfera, $12,75-88$.

Rao, V. B., and J. P. Bonatti, 1987: On the origin of upper tropospheric cyclonic vortices in the South Atlantic Ocean and adjoining Brazil during summer. Meteor. Atmos. Phys., 37, 11-16.

Rossby, C. G., 1939: Relation between varjations in the intensity of the zonal circulation of the atmosphere and the displacements of the semi-permanent centers of action. J. Mar. Res., 2, 38-55.

Virji, H., 1981: A preliminary study of summertime tropospheric circulation patterns over South America estimated from cloud winds. Mon. Wea. Rev., 109, 599-610. 